\title{
COMO ENTENDER A NOMENCLATURA E OS MECANISMOS DE ASSOCIAÇÃO ENTRE OS ANTÍGENOS E OS ALELOS DE HISTOCOMPATIBILDADE COM AS DOENÇAS
}

\author{
HOW TO UNDERSTAND THE NOMENCLATURE AND THE MECHANISMS INVOLVED ON THE \\ ASSOCIATION BETWEEN HISTOCOMPATIBITY ANTIGENS AND ALLELES WITH DISEASE
}

\author{
Eduardo A. Donadi
}

Docente da Divisão de Imonologia Clínica do Departamento de Clinica Médica da Faculdade de Medicina de Ribeirão Preto da Universidade de São Paulo.

CorResPondÊncia: Divisão de Imunologia Clínica do Departamento de Clínica Médica da Faculdade de Medicina de Ribeirão Preto da USP, 14 049-900 Ribeirão Preto, SP - Fax 16-633-6695 - E-mail: eadonadi@fmrp.br

DONADI EA. Como entender a nomenclatura e os mecanismos de associação entre os antígenos e os alelos de histocompatibilidade com as doenças. Medicina, Ribeirão Preto 33: 7-18, jan./mar. 2000.

RESUMO: Devido ao elevado grau de polimorfismo das moléculas e genes do Complexo Principal de Histocompatibilidade e às grandes mudanças ocorridas, recentemente, nos métodos de tipificação desses marcadores, tem havido muita confusão para o não especialista, em relação ao entendimento da nomenclatura do sistema. Além disso, devido ao crescente conhecimento acerca do papel das moléculas de histocompatibilidade na função imune, os mecanismos de associação das moléculas HLA com as doenças ainda constituem tópicos bastante complexos. Esta revisão abrange esses aspectos, tentando facilitar o entendimento da nomenclatura e a relevância desses marcadores imunogenéticos na determinação de susceptibilidade ou resistência às doenças.

UNITERMOS: Antígenos HLA. Nomenclatura. Associação. Doença. Histocompatibilidade.

\section{INTRODUÇÃO}

Para o entendimento dos mecanismos de associação das moléculas de histocompatibilidade com as doenças, é imprescindível conhecer a nomenclatura dos diversos componentes do Complexo Principal de Histocompatibilidade (CPH), os métodos pelos quais os antígenos e os alelos de histocompatibilidade são identificados, e, ainda, a função das moléculas de histocompatibilidade no sistema imune. Assim, torna-se mais fácil compreender os mecanismos pelos quais as moléculas de histocompatibilidade participam da patogenia das doenças, conferindo susceptibilidade ou proteção contra o desenvolvimento dessas enfermidades. Inicialmente, será realizada uma breve apresentação do conjunto de genes que compõem o CPH. Tam- bém serão delineadas as principais características e funções das moléculas codificadas por esses genes. Em seguida, serão abordados os principais métodos, atualmente utilizados para a tipificação dos antígenos e dos alelos de histocompatibilidade. Posto que a nomenclatura do sistema tem sido drasticamente modificada em função do desenvolvimento de novas estratégias para identificar com precisão os alelos de histocompatibilidade, o conhecimento desses métodos facilita também o entendimento da nomenclatura. Finalmente, serão abordados os principais mecanismos propostos para explicar a associação das moléculas HLA com as doenças, as aplicações desses estudos, e, ainda, serão listados alguns trabalhos selecionados, já publicados, acerca da associação HLA e doenças em pacientes brasileiros. 


\section{Os genes do Complexo Principal de Histocompatibilidade}

Os genes do CPH (MHC - "Major Histocompatibility Complex"), na espécie humana, recebem a denominação de sistema HLA (Human Leukocyte Antigen). Esses genes têm sido agrupados em três (03) regiões, didaticamente subdivididas em classe I, II e III, de acordo com as suas localizações no braço curto do cromossomo 6. Atualmente, são reconhecidos mais de 40 loci no CPH humano, codificando diversas moléculas, muitas delas envolvidas diretamente na resposta imune. A região de classe I engloba os loci HLA-A, B, C, E, F, G, H, J, K e L ${ }^{(1)}$. Embora os genes HLA-A, B e $\mathrm{C}$ codifiquem as moléculas clássicas de histocompatibilidade, presentes em praticamente todas as células nucleadas, os genes HLA-E e F codificam moléculas encontradas apenas em tecidos fetais e em alguns tecidos da fase adulta, ao passo que os genes HLA-G codificam moléculas presentes apenas em tecidos placentários ${ }^{(2)}$. Os loci HLA-H, J $\mathrm{K}$ e L não codificam proteínas, sendo denominados pseudogenes. Na região de classe II, são reconhecidos os seguintes genes: HLA-DRA; DRB1-9; DQA 1,2; DQB 1,3; DOA, DOB, DMA; DMB; DPA1,2; DPB1,2; TAP1,2; LMP2,7 e MICA-E ${ }^{(1)}$. Os produtos dos genes HLA-DR, DQ e DP são as moléculas clássicas de histocompatibilidade de classe II, estando envolvidas na rejeição contra enxertos e na apresentação de peptídeos aos receptores dos linfócitos T. Os genes DOA e DOB codificam as cadeias $\alpha$ e $\beta$, respectivamente, produzindo moléculas estruturalmente semelhantes àquelas codificadas pelos genes clássicos de classe $\mathrm{II}^{(3)}$. Existem vários pseudogenes incluídos na região do $\mathrm{CPH}$ de classe II, tais como
DRB2, 6, 7, 8 e 9; DQA2, DQB2 e DQB3, e, ainda, DPA2 e DPB2. Além desses, são também encontrados os genes responsáveis pela codificação de moléculas relacionadas ao processamento, transporte e associação de peptídeos às moléculas do $\mathrm{CPH}$. Os genes LMP 2 e 7 codificam proteassomas que funcionam como endopeptidases, promovendo a degradação de proteínas citosólicas endógenas ou virais em pequenos peptídeos ${ }^{(4)}$. Os produtos dos genes TAP 1 e 2 transportam os peptídeos degradados no citosol para o retículo endoplasmático, facilitando a associação do peptídeo com a molécula $\mathrm{CPH}$ de classe $\mathrm{I}^{(5)}$. As moléculas HLA-DMA e DMB auxiliam no processamento e inserção do peptídeo às moléculas clássicas de histocompatibilidade de classe II ${ }^{(5,6)}$. Os genes MIC (relacionados com a codificação de moléculas relacionadas com as de classe I) foram recentemente incluídos nas categorias MICA, MICB, MICC, MICD e $\mathrm{MICE}^{(1)}$. A região de classe III, além de agregar genes que codificam alguns componentes do sistema do complemento, como C4A, C4B e o fator B, ainda contém genes para as enzimas 21-hidroxilase (21B, 21A), a proteína do choque térmico (Hsp 70) e os fatores de necrose tumoral TNF $\alpha$ e $\beta^{(7)}$. Uma representação esquemática do conjunto de genes do $\mathrm{CPH}$ humano pode ser observada na Figura 1.

\section{As moléculas do Complexo Principal de Histocompatibilidade}

As moléculas de histocompatibilidade são glicoproteínas de superfície que apresentam em comum três porções, uma citosólica, voltada para o interior da célula, responsável pela transdução de sinais intracelulares; outra transmembrana, que mantém a molécula

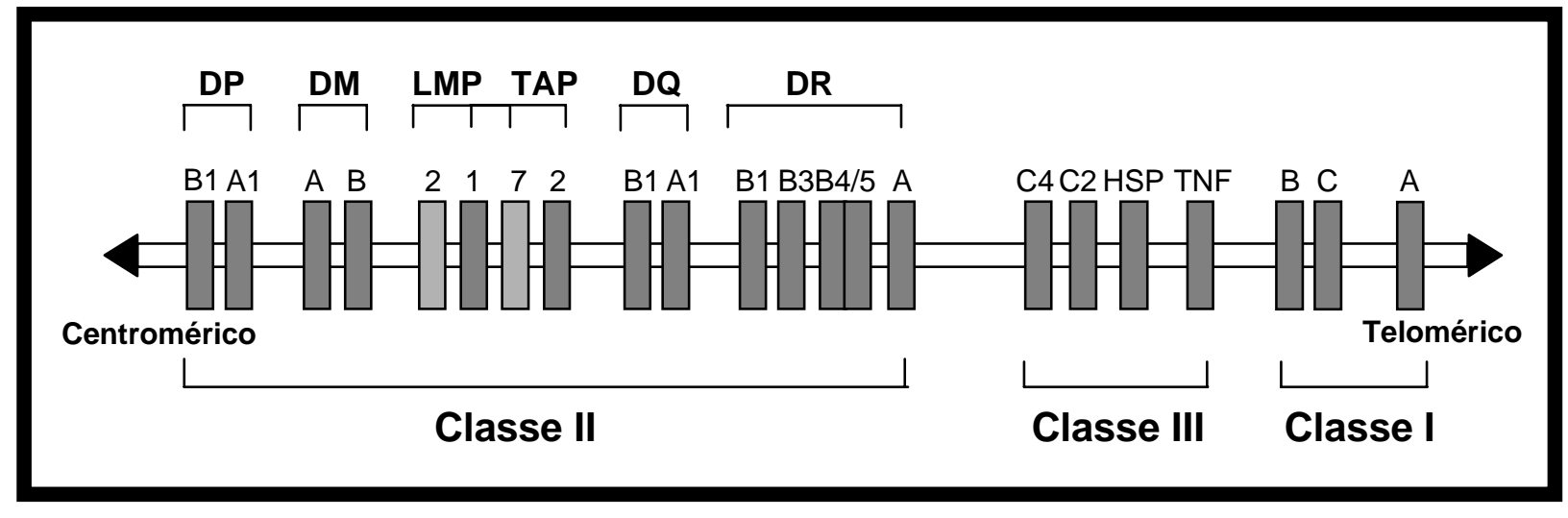

Figura 1 - Estrutura gênica do Complexo Principal de Histocompatibilidade (CPH), humano, no braço curto do cromossomo 6. Os genes de classe I 图 (loci HLA-A, B e C) estão situados mais telomericamente em relação aos outros genes. Os genes clássicos de histocompatibilidade de classe II HLA-DR, DQ, DP $\mathbb{Z}$ e os não clássicos (HLA-DM, LMP e TAP) estão situados mais centromericamente, sendo que cada uma dessas regiões apresenta dois (02) ou mais genes. Os genes de classe III $\square$, embora situados dentro do $\mathrm{CPH}$, não codificam moléculas de histocompatibilidade. 
acoplada à camada bilipídica e, a maior delas, a extracelular, responsável pela apresentação de peptídeos citosólicos/endógenos às células T. As moléculas HLA de classe I são heterodímeros, compostas por uma cadeia pesada $\alpha$, contendo os domínios $\alpha 1, \alpha 2$ e $\alpha 3$, em associação não covalente com a $\beta_{2}$-microglobulina, não polimórfica, codificada por gene situado no cromossomo 15. O grande polimorfismo dessas moléculas é observado nos domínios $\alpha 1$ e $\alpha 2$, sendo o domínio $\alpha 3$ basicamente não polimórfico e apresentando homologia estrutural com as cadeias pesadas das imunoglobulinas. Considerando que os genes para as moléculas HLA-A, B e C são codominates, pelo menos seis (06) dessas moléculas podem ser encontradas nas superfícies celulares $^{(3,7)}$. As moléculas de classe II são também heterodiméricas, compostas por uma cadeia $\alpha$ e uma $\beta$, unidas não covalentemente, ambas codificadas pelos genes do $\mathrm{CPH}$. O polimorfismo dessas moléculas encontra-se nos domínios $\alpha 1$ e $\beta 1$ para as moléculas HLA-DQ e DP, enquanto que, para as moléculas HLA-DR, o polimorfismo ocorre apenas no domínio $\beta 1$ da cadeias $\beta$, sendo sempre não polimórfica a cadeia $\alpha$. Os domínios $\alpha 2$ e $\beta 2$ também apresentam homologia estrutural com as cadeias pesadas das imunoglobulinas.

Dependendo do haplótipo e da complementariedade dos genes DQA1/B1 e DPA1/B1, no mesmo (posição $c i s$ ) ou em haplótipos diferentes (posição trans), até 08 moléculas HLADR e DQ distintas podem ser expressas nas superfícies celulares. $\mathrm{O}$ número de moléculas HLA-DR presentes nas superfícies celulares depende também do haplótipo do indivíduo. Assim, os que apresentam os genes DRB $1 * 01$ e $* 10$ possuem apenas um tipo de molécula $\mathrm{DR} \alpha \beta 1$ (as letras gregas $\alpha$ e $\beta$ designam as cadeias da molécula HLA, ao passo que as letras maiúsculas A e B designam os genes que codificam essas moléculas) por haplótipo, ao passo que os indivíduos portadores dos outros genes DRB1 podem apresentar mais de uma molécula por haplótipo. Os indivíduos tipificados como HLA-DRB $1 * 15$ ou DRB $1 * 16$ possuem as moléculas HLA-DR $\alpha \beta 1$ (moléculas HLA-DR15 ou DR16, conforme identificadas pela sorologia), e, ainda, apresentam as moléculas HLA-DR $\alpha \beta 5$ (genes DRB5*01/02, moléculas HLADR51 na sorologia). Os indivíduos tipificados como HLA-DRB $1 * 03$ ou $* 08$ ou $* 11$ ou $* 12$ ou $* 13$ ou $* 14$ possuem as moléculas DR $\alpha \beta 1$ (HLA-DR3, DR8, DR11, DR12, DR13, DR14 por sorologia), e, ainda, as moléculas HLA-DR $\alpha \beta 3$ (genes HLA-DRB3*02/03, moléculas HLA-DR52, como definidas por sorologia). Os indivíduos tipificados como HLA-DRB $1 * 04$ ou *07 ou *09 possuem as moléculas DR $\alpha \beta 1$ (HLA-DR4, DR7 ou DR9, conforme identificadas pela sorologia), e, ainda, as moléculas HLA-DR $\alpha \beta 4$ (genes HLADRB4*01, moléculas HLA-DR53 por sorologia). O domínio $\alpha 3$ da molécula de classe I e o $\beta 2$ da molécula de classe II fazem a ligação entre as moléculas CD8 e CD4, respectivamente, durante o processo de apresentação do antígeno ${ }^{(1,3,5,7)}$. Uma representação esquemática das moléculas HLA de classe I e II pode ser observada na Figura 2.

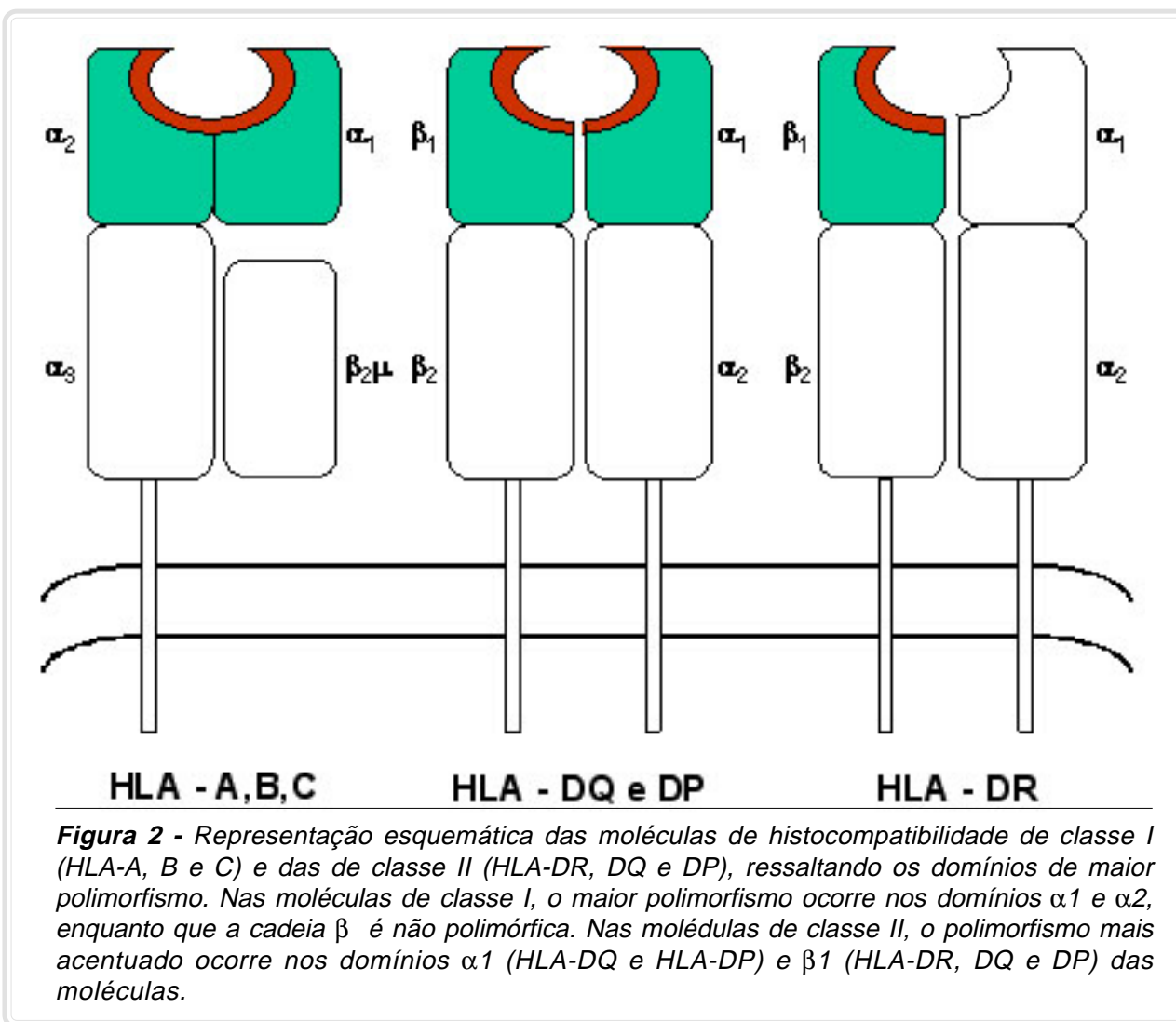


As moléculas de classe I têm uma importante função na apresentação de peptídeos endógenos/virais às células T CD8 positivas. Os peptídeos são gerados no citosol pela ação de proteassomas, como LPM 2 e 7, e, então, transportados ao retículo endoplasmático pelas proteínas TAP 1 e 2, por um mecanismo dependente de ATP. Paralelamente ao processamento dos peptídeos, ainda no retículo endoplasmático, ocorre a síntese da cadeia pesada $\alpha$ e da $\beta_{2}$-microglobulina, com o auxílio da calnexina. $O$ sítio de ligação do peptídeo consiste em uma fenda profunda, formada lateralmente pelas $\alpha$ hélices dos domínios $\alpha 1$ e $\alpha 2$, e o assoalho, por oito (08) fitas $\beta$, pregueadas, desses mesmos domínios, acomodando peptídeos de 9-14 resíduos de aminoácidos. Uma vez formado o heterodímero, o peptídeo se acomoda na fenda, estabilizando a molécula de classe I que, então, pode, via complexo de Golgi, ser exteriorizada e expressa nas superfícies celulares ${ }^{(5,8 / 11)}$.

Uma das principais funções das moléculas de classe II é a de apresentação de peptídeos às células CD4 positivas. A fenda de ligação ao peptídeo, presente na molécula de classe II, é semelhante àquela da molécula de classe I, no entanto, pode acomodar peptídeos de 15 a 24 resíduos de aminoácidos . Os peptídeos apresentados por essas moléculas são processados, em meio ácido, por proteases, como as catepsinas B e D, presentes no endossoma e lisossoma das células apresentadoras de antígenos. Enquanto o processamento do peptídeo está ocorrendo no compartimento lisossomal, no retículo endoplasmático, com o auxílio da calnexina, as cadeias $\alpha$ e $\beta$ estão sendo associadas na presença de uma terceira cadeia (invariante-Ii), que bloqueia o sítio de ligação ao peptídeo. No complexo trans-Golgi, as moléculas de class II se unem aos compartimentos endo/lisossomais, onde proteases ácidas e as moléculas HLA-DMA e DMB removem a cadeia invariante, permitindo, assim, que a molécula se ligue ao peptídeo e se expresse na superfície celular ${ }^{(4,5,12,13,14)}$.

Os genes do CPH são os mais polimórficos de todos os genes dos mamíferos. De acordo com a última nomenclatura dos fatores do sistema HLA, quase 1000 alelos de classe I e II já haviam sido relatados ${ }^{(1)}$. Assim, o número de moléculas distintas também é praticamente da mesma quantidade. Estudos moleculares têm mostrado que as regiões de maior polimorfismo estão localizadas no sulco de ligação ao peptídio. Se a manutenção do polimorfismo dessas moléculas está relacionada com a proteção ou susceptibilidade a doenças infecciosas ou com uma seleção negativa mais eficiente de clones auto-reativos, são questões que, ainda, merecem outros estudos ${ }^{(15 / 18)}$.

\section{Métodos de detecção do polimorfismo das moléculas e dos genes de histocompatibilidade}

O polimorfismo das especificidades HLA pode ser detectado em nível celular ou molecular. Em nível celular, os procedimentos iniciais utilizavam o método de aglutinação para detecção de antígenos leucocitários. No entanto, em 1964, Terasaki \& McClelland descreveram um micrométodo de citotoxicidade mediada por anticorpo e dependente de complemento mais adequado para a detecção desses antígenos leucocitários, sendo até hoje empregado ${ }^{(19)}$. Os progressos alcançados para os métodos sorológicos dizem respeito à melhoria dos procedimentos de separação de linfócitos $\mathrm{B}$, indispensáveis para a detecção das especificidades HLA de classe II, e, também, à obtenção de anticorpos monoclonais para diversas especificidades de classe I e II. Os métodos sorológicos dependem de uma separação adequada de linfócitos totais e de linfócitos B, de células viáveis, de expressão adequada das moléculas de histocompatibilidade na superfície celular, de disponibilidade de painel de anti-soros específicos, dentre outros fatores ${ }^{(20)}$. Outro método celular, bastante utilizado nos anos 70 e 80, particularmente para definição de especificidades HLA de classe II não detectadas pela sorologia, e, também, para seleção de doadores em transplantes de medula óssea, foi a cultura mista de linfócitos, utilizando-se células com fenótipo conhecido, definindo as especificidades HLA, denominadas HLA-Dw ${ }^{(21)}$.

No final dos anos 80, e durante os anos 90, houve um grande avanço nos procedimentos de tipificação dos alelos HLA, utilizando-se o DNA genômico. Um dos primeiros foi o método de avaliação dos tamanhos dos fragmentos de DNA, produzidos pela digestão com endonucleases de restrição ("restriction fragment length polymorphism"-RFLP). O DNA é extraído de células nucleadas, digerido com enzimas de restrição e os fragmentos gerados são separados, de acordo com o seu tamanho, em géis de agarose. O DNA é desnaturado e os seus fragmentos são hibridados com sondas (marcadas com isótopos radioativos) de DNA complementar para o lócus a ser estudado. O padrão de bandas obtidas define a especificidade. O método é de baixa resolução e de execução demorada ${ }^{(22)}$.

A segunda geração de métodos moleculares utiliza DNA amplificado pela reação em cadeia da polimerase ("polymerase chain reaction" - PCR) e sondas ou iniciadores ("primers") de oligonucleotídeos de seqüência, específicos. No método denominado "sequence-specific primers" (SSP), são realizadas 
várias reações de amplificação, cada uma delas contendo um iniciador capaz de detectar um alelo ou um grupo de alelos. Os iniciadores que amplificaram nessa reação são visualizados em géis de agarose ${ }^{(23)}$. Dentre os métodos que utilizam conjuntos de sondas de sequiência específicas, o SSOP ("sequence-specific oligonucleotide probes") é um dos mais populares. Nesse procedimento, o DNA é amplificado com um par de iniciadores que identifica uma região comum ou genérica da especificidade a ser tipificada. O DNA amplificado é desnaturado e fixado em membrana de "nylon". As sondas marcadas, por exemplo com a digoxigenina, são incubadas, separadamente, com os DNAs desnaturados, em temperatura adequada para ocorrer a hibridação. Um anticorpo de antidigoxigenina, marcado com fosfatase alcalina, reconhece a sonda que se ligou à membrana. A adição de um substrato, que emite luz sob a ação da fosfatase alcalina, sensibiliza um filme radiográfico, discriminando o grupo de alelos ou o alelo específico ${ }^{(22,24)}$.

Quando, com os métodos acima descritos, não se consegue discriminar os alelos desconhecidos, tenta-se construir novas sondas específicas, ou, então, procede-se ao seqüenciamento das bases nitrogenadas. O seqüenciamento pode ser realizado manualmente ou utilizando seqüenciador automático. No método manual, o DNA é amplificado com iniciadores genéricos da região a ser seqüenciada, digerido com enzimas de restrição e inserido em um vetor. O DNA recombinante é, então, introduzido em bactérias susceptíveis, extraído e, a seguir, sequienciado ${ }^{(25)}$.

\section{Nomenclatura dos antígenos e genes de histocompatibilidade}

A nomenclatura das especificidades HLA é normatizada por um Comitê Internacional que se reúne regularmente para atribuir novos nomes aos genes recentemente descobertos, ou, ainda, mudar a estrutura da nomenclatura vigente. Nas décadas de 70 e 80 , os objetivos desse Comitê estavam dirigidos à normatização das nomenclaturas das especificidades HLA, definidas pelos métodos sorológicos ou celulares. Assim, devido à falta de conhecimento da extensão do polimorfismo do $\mathrm{CPH}$, e, também, devido a não disponibilidade de procedimentos metodológicos para avaliação em larga escala do polimorfismo do $\mathrm{CPH}$, as especificidades HLA eram designadas por um (01) ou dois (02) dígitos após a identificação do locus HLA de classe I ou II. Assim, com os métodos sorológicos, as especificidades HLA eram definidas da seguinte forma para o locus HLA-A: HLA-A1, HLA-A2, HLA-3, HLA-A9, HLA-A10 ,etc, até o HLA-A74; para o locus HLA-B: HLA-B5, HLA-B7, HLA-B8, HLA-B12 etc, até o HLA-B78; para o locus HLA-C: HLA-Cw1 até o Cw10. A letra "w" (inicial da palavra, em inglês, Workshop) era utilizada em quatro (04) eventualidades: 1) no locus HLA-C, a letra era colocada para se evitar confusão com a nomenclatura do Sistema do Complemento, cujos componentes são designados como C1, C2, C3 etc.; 2) nos outros loci de classe I ou II a letra "w" também era colocada na frente do nome do locus para designar que aquela nomenclatura era provisória. Assim que a identidade do antígeno era definida, após tipificação em vários laboratórios de referência, a nomenclatura era definida, e então, a letra "w" era retirada. Assim, o antígeno HLA-Bw51, após definição que era uma especificidade diferente do antígeno HLA-Bw52, passava a ser denominado simplesmente HLA-B51; 3) Os antígenos HLA-Bw4 e HLA-Bw6 são definidos como antígenos públicos, posto que os anti-soros anti-Bw4 e Bw6 reagiam com diversos antígenos HLA-B bem definidos. Atualmente, sabe-se que esses anticorpos reagiam com estruturas compartilhadas pelas moléculas HLA-B, dividindo-as em dois (02) grandes grupos, as que reagiam com o anticorpo anti-HLA-Bw4 e aquelas que reagiam com o anti-HLA-Bw6; 4) As especificidade de classe II, definidas pelos métodos celulares, não podiam ser classificadas exatamente como aquelas identificadas pela sorologia. Assim, as tipificações definida por métodos celulares eram todas incluídas sob a denominação HLA-Dw. Mais tarde, com o advento das metodologias utilizando o DNA genômico, verificou-se que, em algumas dessas tipificações, os alelos eram mesmo incluídos dentro das especificidades HLA-DR, como o HLA-Dw4 e o HLA-Dw14, ambos subtipos do antígeno HLA-DR4, atualmente designados como HLA-DRB $1 * 0401$ e 0404, respectivamente. Em outras situações, as especificidades definidas como HLA-Dw eram, na verdade, alelos pertencentes à região HLA-DQ, exemplo HLA-Dw1, sendo, atualmente, designado como HLA-DQB1*0101. A nomenclatura atual elimina a letra " $w$ " em todas essas situações, exceto na denominação do locus HLA-C, justamente para não confundir com a nomenclatura do Sistema do Complemento ${ }^{(1)}$.

Um outro tipo de confusão, relacionada à falta de discriminação do polimorfismo das especificidades de classe I e II pelos métodos sorológicos ou celulares, refere-se aos antígenos que são subtipos (splits) 
de outros já definidos. Exemplos: HLA-A10 (splits HLA-A24 e A25), HLA-B5 (HLA-B51 e B52), HLADR2 (HLA-DR15 e HLADR16), HLA-DR6 (HLADR13 e HLA-DR14) e HLA-DQ1 (HLA-DQ5 e HLA-DQ6). Atualmente, com o advento dos métodos moleculares, esses problemas não mais existem, pois os alelos já são definidos especificamente ${ }^{(1)}$.

Devido ao extenso polimorfismo dos genes HLA, no final dos anos 80 e início dos anos 90, o Comitê Internacional decidiu fazer uma mudança importante no sistema de nomenclatura desses genes. Os loci de classe I continuaram com a mesma denominação, ou seja, HLA-A, HLA-B e HLA-Cw, porém, aumentando o número total de dígitos para quatro (04), com a finalidade de abranger todo o polimorfismo já identificado, bem como visando o polimorfismo a ser definido no futuro. Os dois (02) primeiros dígitos referem-se às tipificações sorológicas e os dois (02) seguintes ao alelo específico. Assim, o gene que codifica a molécula HLA-A1 passou a ser denominado HLA-A*01, contendo os alelos HLA-A*0101, *0102 e*0103. Uma vez que as especificidades de classe II possuem mais de uma cadeia polimórfica, o Comitê, além de introduzir os quatro (04) dígitos, acrescentou os nomes das cadeias $\alpha$ ou $\beta$ da molécula de histocompatibilidade na nomenclatura, identificados com as letras A ou B, conforme já mencionado. Assim, o gene que codifica a molécula HLA-DR1 passou a ser denominado HLA-DRB1*01, abrangendo os alelos DRB1*0101, $* 0102, * 0103$ e *0104, sendo a letra B representativa da cadeia $\beta$, altamente polimórfica nos genes HLADR. Posto que a região HLA-DR possui diversos genes para as cadeias $\beta$, cada locus recebe o número correspondente, como HLA-DRB $1 * 0101$, HLADRB3*0101, HLA-DRB4*0101 e HLA-DRB5*0101. O polimorfismo dos genes HLA-DQ e DP ocorre tanto na cadeia $\alpha$ como na $\beta$, sendo, então, designados genes HLA-DQA1/ DQB1 ou HLA-DPA1/DPB1. Em algumas situações, um quinto dígito é adicionado à denominação do alelo, indicando que, embora exista uma substituição de um nucleotídeo no genoma, a sequiência de resíduos de aminoácido é mantida por ocasião da codificação das moléculas de histocompatibilidade. Assim, os alelos HLA-DRB $1 * 01021$ e *01022 codificam moléculas com a mesma seqüência de aminoácidos, diferindo apenas em nível genômico. Finalmente, nos casos em que o gene, embora presente no DNA, não codifica a respectiva proteína, introduz-se a letra $\mathrm{N}$ (referente a nulo) no final da denominação do alelo, exemplo HLA-A*0104N ${ }^{(1)}$. A Tabela I sumaria os loci de histocompatibilidade, definidos na última nomenclatura, assim como os números de alelos em cada loci, identificados até o presente.

\begin{tabular}{|cc|}
\hline $\begin{array}{c}\text { Tabela I - Número de alelos dos diversos loci do } \\
\text { Complexo Principal de Histocompatibilidade }\end{array}$ \\
\hline Locus & Número de alelos \\
\hline HLA-A & 124 \\
HLA-B & 258 \\
HLA-C & 74 \\
HLA-E & 5 \\
HLA-G & 14 \\
HLA-DRB1 & 221 \\
HLA-DRB3 & 19 \\
HLA-DRB4 & 9 \\
HLA-DRB5 & 14 \\
HLA-DRB6 & 3 \\
HLA-DRB7 & 2 \\
HLA-DQA1 & 19 \\
HLA-DQB1 & 39 \\
HLA-DPA1 & 15 \\
HLA-DPB1 & 84 \\
HLA-DOA & 8 \\
HLA-DMA & 4 \\
HLA-DMB & 5 \\
TAP1 & 5 \\
TAP2 & 6 \\
MICA & 15 \\
\hline
\end{tabular}

\section{Associação HLA com doenças}

No final dos anos 60, os primeiros estudos referentes à associação entre os antígenos de histocompatibilidade e doenças mostraram resultados inconsistentes na avaliação de doenças como o linfoma de Hodgkin e a leucemia linfóide aguda ${ }^{(26)}$. No início dos anos 70 , foi relatada a importante associação do antígeno HLA-B27 com a espondilite anquilosante ${ }^{(27)}$. Desde então, os antígenos HLA têm sido estudados em uma grande variedade de doenças de distintas etiologias, incluíndo as auto-imunes, as infecciosas, as neoplásicas e as idiopáticas. Dois tipos de estudos têm sido utilizados para abordar essa associação, os populacionais e os familiares. Nos estudos populacionais, as freqüências dos antígenos HLA, observadas em um grupo de pacientes não aparentados, são comparadas com aquelas de indivíduos-controle, também não aparentados. Quando uma associação é estabelecida 
em estudos populacionais, é útil realizar os estudos familiares para um melhor entendimento de suas bases genéticas. A ocorrência de associação é avaliada pela comparação das freqüências dos antígenos em pacientes e indivíduos-controle, sendo a significância estimada pelo teste exato de Fisher ou pelo Chi-quadrado. A força da associação é calculada pelo risco relativo (RR), pela fração etiológica (FE) ou pela fração preventiva (FP). O RR indica quão mais frequiente uma doença ocorre em indivíduos portadores de um determinado antígeno HLA em relação aos indivíduos que não apresentam o marcador. Nos casos em que o RR é maior do que 1, a freqüência do marcador, nos pacientes, é maior do que nos indivíduos-controle, e, quando é menor do que 1 , tem significado inverso. Quando o RR é maior do que 1, o cálculo da FE estima a magnitude de susceptibilidade em termos populacio- nais. Em contraste, nos casos em que o RR é menor do que 1, a FP estima a magnitude de proteção, também em termos populacionais ${ }^{(28,29)}$. A Tabela II sumaria as fórmulas para os cálculos do RR, FE e FP.

Uma vez estabelecida uma associação entre um antígeno HLA com uma determinada doença, devese entender o significado desse fenômeno. Várias hipóteses têm sido aventadas para explicar os possíveis mecanismos implicados nessa associação. Primeira: as moléculas de histocompatibilidade podem funcionar como receptores para alguns agentes etiológicos. Desde que algumas glicoproteínas de superfície, como C3d e CD4, têm sido associadas como porta de entrada para os vírus Epstein-Barr e HIV, respectivamente, é possível que as moléculas HLA, que também são glicoproteínas, possam desempenhar um papel similar, criando a possibilidade de que alguns

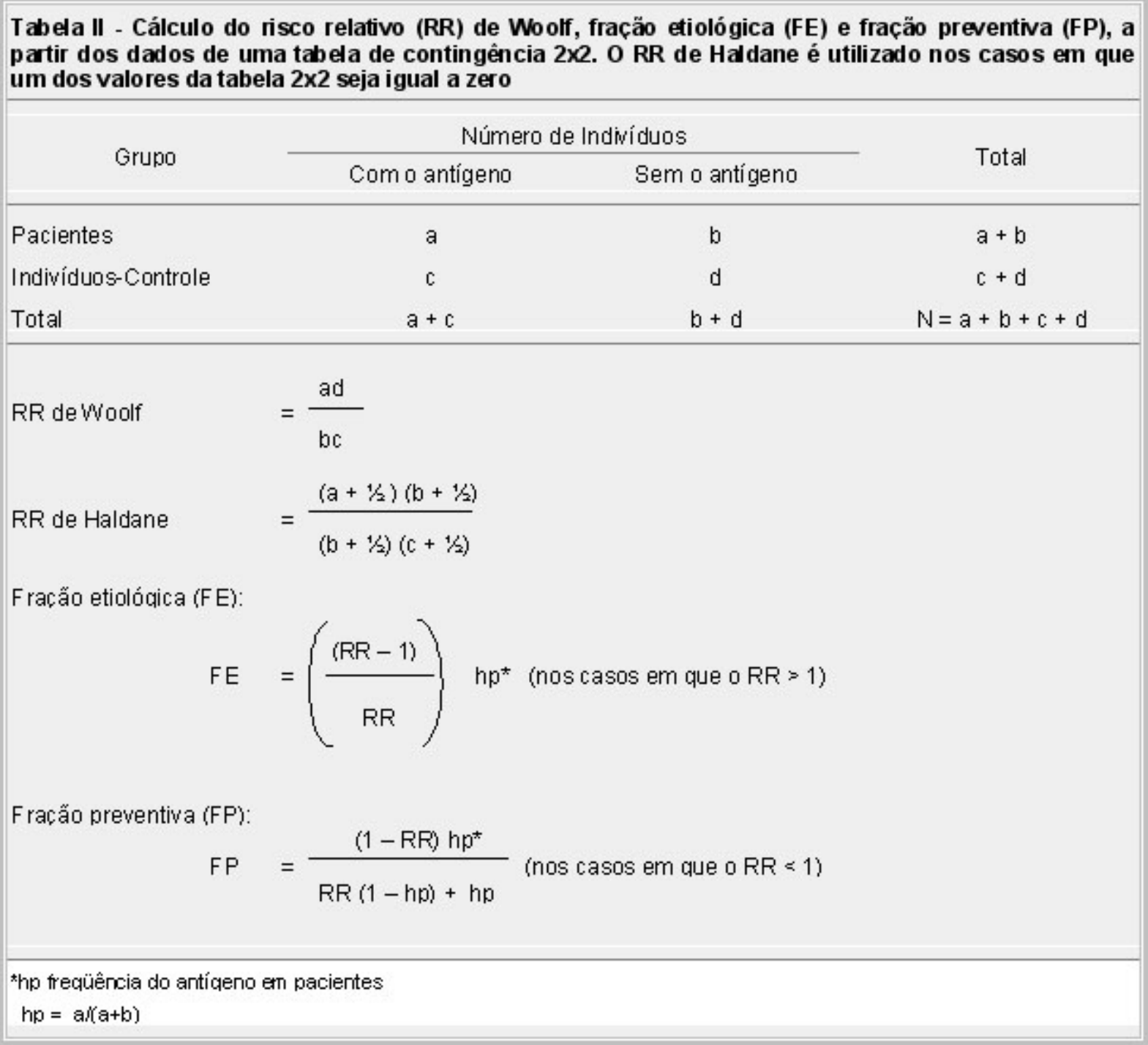


tipos de moléculas possam facilitar ou impedir a entrada dos vírus. No entanto, têm sido documentadas apenas interações dos vírus Semliki e os adenovírus com as moléculas HLA de classe I e do vírus da desidrogenase lática com as moléculas de classe II. Segunda: a molécula HLA seleciona o peptídeo antigênico a ser apresentado ao linfócito $T$. Estudos em modelos experimentais e em procedimentos in vitro para medir a afinidade física entre moléculas do $\mathrm{CPH}$ e os peptídeos têm demonstrado que uma mesma molécula pode se ligar a peptídeos distintos com afinidades diferentes. De interesse particular é o relato de que o antígeno HLA-B53 protege contra o desenvolvimento de manifestações graves da malária em pacientes da Zâmbia, sendo inclusive identificada a ligação de um peptídeo imunodominante do parasita com a molécula HLA-B53. Terceira: mimetismo molecular entre os antígenos HLA e os agentes etiológicos. Anticorpos dirigidos contra a enterobactéria Klebsiella reagem com linfócitos de indivíduos HLA-B27, portadores de espondilite anquilosante. Ainda, anticorpo monoclonal anti-HLA-B27 reage cruzadamente com várias enterobactérias como a Klebsiella, Salmonella, Shigella e Yersinia. Quarta: indução aberrante de expressão moléculas HLA de classe II. Células teciduais que normalmente não expressam moléculas HLA de classe II podem ser estimuladas a apresentá-las na presença de citocinas, derivadas, por exemplo, de células infectadas por vírus. Assim, essas células podem apresentar aos linfócitos T antígenos derivados da degradação do próprio tecido, gerando uma resposta auto-imune. Quinta: participação de outros genes do $\mathrm{CPH}$, ou mesmo de fora do CPH, que estejam em desequilíbrio de ligação com os genes de histocompatibilidade. Alguns fatores do complemento, os fatores de necrose tumoral, os peptídeos processadores e transportadores de determinantes antigênicos, as proteínas do choque térmico, todos têm algum papel na resposta imune, sendo codificados por genes situados dentro do CPH. Da mesma forma que os genes de classe I podem estar em desequilíbrio de ligação com os de classe II, é possível que esses também estejam em desequilíbrio com os outros genes d e dentro ou de fora do $\mathrm{CPH}^{(30 / 34) \text {. }}$

\section{A associação HLA e doenças em brasileiros}

Relativamente, poucos trabalhos têm sido publicados, abordando o estudo da associação entre antígenos de histocompatibilidade e doenças em indivíduos brasileiros. Os estudos encontrados nos inde- xadores latino-americanos e internacionais abrangem as seguintes patologias: febre reumática ${ }^{(35,36)}$, pênfigo foliáceo ou fogo selvagem ${ }^{(37,38,39)}$, cromoblastomicose $^{(40)}$, leishmaniose cutânea ${ }^{(41)}$, paracoccidioidomico$\mathrm{se}^{(42,43)}$, esquistossomose ${ }^{(44)}$, diabetes mellitus, tipo $\mathrm{I}^{(45)}$, malária ${ }^{(46)}$, miastenia gravis ${ }^{(47)}$, deficiência de 21-hidroxilase ${ }^{(48)}$, hepatite crônica ${ }^{(49,50)}$, glaucoma ${ }^{(51)}$, descolamento de retina ${ }^{(52)}$, angioedema hereditário ${ }^{(53)}$, artrite reumatóide do adulto ${ }^{(5)}$, artrite reumatóide juvenil $^{(55)}$ lúpus eritematoso sistêmico ${ }^{(56 / 59)}$, associação de doenças do tecido conjuntivo ${ }^{(60)}$, ataxia cerebelar ${ }^{(61)}$, doença de Chagas ${ }^{(62)}$, doença de Graves ${ }^{(63,64)}$, síndrome de Alport ${ }^{(65)}$, leucemias agudas e aplasia de medula óssea $^{(66)}$ e coréia de Sydenham ${ }^{(67)}$.

\section{Contribuições dos estudos acerca da susceptibilidade imunogenética}

A suposição de que um marcador imunogenético pudesse ter importância no diagnóstico de doenças foi, inicialmente, aventada, em relação à associação da espondilite anquilosante com o antígeno HLA-B27. No entanto, essa idéia não pôde ser posteriormente confirmada, por vários motivos, como: a positividade do antígeno é variável em indivíduos normais e em pacientes de diferentes etnias; em outras espondiloartopatias, como a síndrome de Reiter, a artrite psoriática e as enteroartropatias o marcador também ocorre em frequiência mais baixa; e, ainda, estudos populacionais sobre a incidência de espondilite anquilosante, em indivíduos normais HLA-B $27^{+}$, mostram resultados inconclusivos $^{(68)}$.

Em relação ao tratamento e à prevenção de doenças, tem sido relatado que os pacientes com artrite reumatóide, portadores da dupla heterozigose HLADRB1*0401 e *0404, apresentam doença articular mais grave e mais rapidamente progressiva. Assim, o tratamento precoce desses pacientes, com drogas remissivas de ação lenta e com imunossupressores, poderia impedir o desenvolvimento de deformidades. Mais recentemente, tem sido preconizado o tratamento preventivo de pacientes com história familiar de diabetes mellitus do tipo I, apresentando altos títulos de autoanticorpos contra antígenos pancreáticos e positividade para o alelo HLA-DQB $1 * 0302^{(69)}$.

O motivo pelo qual a diversidade alélica dos genes do complexo principal de histocompatibilidade (ou o polimorfismo das moléculas codificadas por esses genes) tem sido conservada durante a evolução ainda não está esclarecido. Assim, o papel do polimorfismo dessas moléculas, na determinação de susceptibilidade ou resistência às doenças, tem merecido 
bastante atenção. $\mathrm{O}$ rastreamento de alelos de histocompatibilidade, em diversos grupos étnicos de diferentes áreas geográficas, apontam que a conversão gênica e a mutação de ponto sejam os principais mecanismos de geração de diversidade alélica em nível populacional, sendo que os locais de maior polimorfismo se encontram nas regiões das cadeias $\alpha$ e $\beta$, que estão em contacto com os peptídeos antigênicos. Uma explicação razoável para essa observação é que a diversidade alélica tenha sido gerada em decorrência da interação com os agentes patogênicos ${ }^{(10,15,16,17)}$. O estudo do polimorfismo da população africana, cuja diversidade alélica é, pelo menos, o dobro daquela observada na população caucasiana européia, sugere algumas explicações. O antígeno HLA-B53, em indivíduos da África Ocidental, protege contra o desenvolvimento da forma grave da malária, sendo responsabilizado pela diminuição da incidência da doença nessa região ${ }^{(70,71)}$. Por outro lado, a especificidade HLA-DRB $1 * 0101$ confere resistência à malária na África Ocidental, ao passo que a especificidade HLADRB1*1301 é responsável pela resistência à doença na África Oriental. Assim, é possível que o extraordinário polimorfismo observado nessas populações tenha se desenvolvido, primariamente, por intermédio de seleção de moléculas induzidas pelo patógeno ${ }^{(72,73)}$.

Comparadas com as outras populações, as indígenas apresentam polimorfismo de alelos HLA re- lativamente baixo, refletindo, presumivelmente, o isolamento geográfico a que essas populações estão confinadas ${ }^{(17)}$. Poucos estudos sobre a associação HLA e doenças têm sido conduzidos nesses grupos, e, em número ainda mais reduzido, em indígenas brasilei$\operatorname{ros}^{(74)}$. A população nativa africana, como já mencionado, tem sido objeto de muitos estudos imunogenéticos, particularmente aqueles de associação com doenças infecciosas ${ }^{(75)}$. Os orientais apresentam também características peculiares em relação aos marcadores de susceptibilidade a doenças, usualmente, diferentes daqueles observados em indivíduos cauca$\operatorname{sianos}^{(76,77)}$. As populações caucasianas, evidentemente, são as mais estudadas, abrangendo doenças de diversas etiologias ${ }^{(78)}$. Nas populações miscigenadas, como a brasileira, o polimorfismo ocorre, provavelmente, pela agregação de alelos de vários grupos previamente separados, cada qual possuindo um conjunto distinto de alelos, mais do que pela seleção natural de um grande número de alelos ${ }^{(17)}$. Se, de um lado a diversidade alélica pode dificultar a identificação de marcadores imunogenéticos de baixo poder de associação, por outro lado, pode trazer contribuições, identificando novas associações, ou mesmo reforçando aquelas já existentes. Assim, os estudos das características de todas essas populações podem contribuir para o entendimento da associação entre os antígenos de histocompatibilidade e as doenças.

DONADIEA. Houw to understand the nomenclature and the mechanisms involved on the association between histocompatibility antigens and alleles with disease. Medicina, Ribeirão Preto 33: 7-18, jan./march 2000.

ABSTRACT: Due to the extensive degree of polymorphism of histocompatibility molecules and alleles, the continued changing of HLA nomenclature, the large recent developments for HLA typing methods at molecular level, and the growing knowledge of the function of HLA molecules in the immune response, the issue regarding the mechanisms of HLA and disease association have yielded much confusion between the HLA non-specialists. The aim of this revision is to facilitate the comprehension of the nomenclature of the Major Histocompatibility Complex, and to overview the current status of the topic HLA and disease association.

UNITERMS: HLA Antigens. Nomenclature. Disease. Association. Histocompatibility.

\section{REFERÊNCIAS BIBLIOGRÁFICAS}

1 - BODMER JG; MARSH SGE; ALBERT ED; BODMER WF; BONTROP RE; DUPONT B; ERLICH HA; HANSEN JA; MACHB; MAYR WR; PARHAM P; PETRESDORF EW; SASAZUKI T; SCHNEUDER GHTH; STROMINGER JL; SVEJGAARD A \& TERASAKI PI. Nomenclature for factors of the HLA system, 1998. Tissue Antigens 53: 407-443, 1999.
2 - CAROSELLA ED; DAUSSET J \& KIRSZENBAUM M. HLA-G revisited. Immunol Today 17: 407-409, 1996.

3 - NEPOM BS \& NEPOM GT. Polyglot and polymorfism - An HLA updade. Arthritis Rheum 38: 1715-1721, 1995.

4 - DRISCOLL J; BROWN MG; FINLEY D \& MONACO JJ. MHClinked LMP gene products specifically alter peptidase activities of the proteasome. Nature 365: 262-264, 1993. 
5 - BRODSKY FM; LEM L \& BRESNAHAN PA. Antigen processing and presentation. Tissue Antigens 47: 464-471, 1996.

6 - SADEGH-NASSERI S \& GERMAIN RN. How MHC class II molecules work: peptide-dependent completion of protein folding. Immunol Today 13: 43-46, 1992.

7 - NEPOM GT \& NEPOM B. Genetics of the major histocompatibility complex in rheumatoid arthritis. In: KLIPPEL JH \& DIEPPE PA, eds. Rheumatology, $2^{\text {nd }}$ ed, Mosby, St. Louis, v.1, p.5 7.1- 5 7.12, 1998.

8 - ANDERSON KS; ALEXANDER J; WEI M \& CRESSWELL P. Intracellular transport of class I MHC molecules in antigen processing mutant cell lines. J Immunol 151: 3407-3419, 1993.

9 - ACCOLLA RS; ADORINI L; SARTORIS S; SINIGAGLIA F \& GUARDIOLA J. MHC: orchestrating the immune response. Immunol Today 16: 8-11, 1995.

10 - POWIS SH \& GERAGHTY DE. What is the MHC? Immunol Today 16: 466-468, 1995.

11 - GROETTRUP M; SOZAA; KUCKELKORN U \& KLOETZEL PM. Peptide antigen production by the proteasome: complexity provides efficiency. Immunol Today 17: 429-435, 1996.

12 - BROWN JH; JARDETZKY TS; GORGA JC; STERN LJ; URBAN RG; STROMINGER JL \& WILEY DC. Three-dimensional structure of the human class II histocompatibility antigen HLADR1. Nature 364: 33-39, 1993.

13 - UNANUE ER. Cellular studies on antigen presentation by class II MHC molecules. Curr Opinion Immunol 4: 63-69, 1992.

14 - MORRIS P; SHAMAN J; ATTAYAM; AMAYAM; GOODMAN S; BENGMAN C; MONACO JJ \& MELLINS E. An essential role for HLA-DM in antigen presentation by class II major histocompatibility molecules. Nature 368: 551-558, 1994.

15 - RILEY E \& OLERUP O. HLA polymorphisms and evolution. Immunol Today 13: 333-335, 1992.

16 - CLAYTON J \& GEE H. Major histocompatibility complex: the evolutionary angle. Nature 365: 111-112, 1993.

17 - PARHAM P. HLA, anthropology, and transplantation. Transpl Proc 25: 159-161, 1993.

18 - KRONENBERG M; BRINES R \& KAUFMAN J. MHC evolution: a long term investment in defense. Immunol Today 15: 4-6, 1994.

19 - TERASAKI PI \& McCLELLAND JD. Microdroplet assay of human serum cytotoxins. Nature 204: 998-1000, 1964.

20 - DARKE C \& DYER P. Clinical HLA typing by cytotoxicity. In: DYER P \& MIDDLETON D, eds. Histocompatibility testing: a practical approach. Oxford University Press, Oxford, p.51-80, 1995.

21 - REINSMOEN NL. Cellular methods. In: DYER P \& MIDDLETON $D$, eds. Histocompatibility testing: a practical approach. Oxford University Press, Oxford, p.143-57, 1995.

22 - SAVAGE D; BAXTER-LOWE LA; GORSKI J \& MIDDLETON D. Molecular methods. In: DYER P \& MIDDLETON D, eds. Histocompatibility testing: a practical approach. Oxford University Press, Oxford, p.107-142, 1995.
23 - OLERUP O \& ZETTERQUIST H. HLA-DR typing by PCR amplification with sequence-specific primers (PCR-SSP) in two hours: an alternative to serological DR typing in clinical practice including donor-recipient matching in cadaveric transplantation. Tissue Antigens 39: 225-235, 1992.

24 - MICKELSON E; SMITH A; MCKINNEY S; ANDERSON G \& HANSEN JA. A comparative study of HLA-DRB1 typing by standard serology and hybridization of non-radioactive sequence-specific oligonucleotide probes to PCR-amplified DNA. Tissue Antigens 41: 86-93, 1993.

25 - SANGER F; NICKLEN S \& COULSON AR. DNA sequencing with chain-terminating inhibitors. Proc Natl Acad Sci USA 74 : 5463-5467, 1977.

26 - WALFORD RL; FINKELSTEIN S; NEERHOUT R; KONRAD P \& $S H A N B R O M E$. Acute childhood leukemia in relation to the HL-A human transplantation genes. Nature 231: 461-462, 1970.

27 - SCHLOSSTEIN L; TERASAKI PI; BLUESTONE R \& PEARSON CM. High association of an HL-A antigen, w27, with ankylosing spondylitis. N Engl J Med 288: 704-706, 1973.

28 - SVEJGAARD A. HLA and disease. In: ROSE NR; FRIEDMAN $H$ \& FAHREY JL, eds. Manual of clinical laboratory imunology, 3rd ed, American Society for Microbiology, Washington D C, p.912-920, 1986.

29 - SVEJGAARD A \& RYDER LP. HLA and disease associations: Detecting the strongest association. Tissue Antigens 43: 18-27, 1994.

30 - SVEJGAARD A;PLATZP;RYDER LP; NIELSEN LS \& THOMSEN M. HL-A and disease associations - A Survey. Transplant Rev 22: 3-43, 1975.

31 - TIWARI JL \& TERASAKI PI. Mechanisms of HLA and disease associations. In: TIWARI JL \& TERASAKI PI, eds. HLA \& disease association, Springer-Verlag, New York, p. 28$31,1985$.

32 - BRODSKY FM. Antigen presentation \& the major histocompatibility complex. In: STITES DP; TERR AI \& PARSLOW TG, eds. Medical immunology, $9^{\text {th }}$ ed, Appleton \& Lange, Stanford, p. 83- 94, 1997.

33 - LECHLER R. The roles of class I and II molecules of the major histocompatibility complex in T-cell immunity. In: LECHLER R, ed. HLA \& disease. Academic Press, London, p. 49-72, 1994.

34 - LECHLER R. Mechanisms of HLA and disease associations. In: LECHLER R, ed. HLA \& disease. Academic Press, London, p.83-91, 1994.

35 - GUILHERME L; WEIDEBACH W; KISS MH; SNITCOWSKY R \& KALIL J. Association of human leukocyte class II antigens with rheumatic fever or rheumatic heart disease in a Brazilian population. Circulation 83: 1995-1998, 1991.

36 - WEIDEBACH W; GOLDBERG AC; CHIARELLA JM; GUILHERME L; SNITSCOWSKY R; PILEGGI F \& KALIL J. HLA class II antigens in rheumatic fever. Analysis of the DR locus by restriction fragment-length polymorphism and oligotyping. Hum Immunol 40: 253-258, 1994

37 - PETZ-ERLER ML \& SANTAMARIA J. Are HLA class II genes controlling susceptibility and resistance to Brazilian pemphigus foliaceus (fogo selvagem)? Tissue Antigens 33: 408-414, 1989. 
38 - MORAES JR; MORAES ME; FERNANDEZ-VINA M; DIAZ LA; FRIEDMAN H; CAMPBELL IT; ALVAREZ RR; SAMPAIO AS; RIVITTI EA \& STASTNY P. HLA antigens and risk for development of pemphigus foliaceus (fogo selvagem) in endemic areas of Brazil. Immunogenetics 33: 388-391, 1991.

39 - CERNA M; FERNANDEZ-VINA M; FRIEDMAN H; MORAES JR; MORAES ME; DIAZ L \& STATSNY P. Genetic markers for susceptibility to endemic Brazilian pemphigus foliacus (fogo selvagem) in Xavante Indians. Tissue Antigens 42: 138140, 1993.

40 - TSUNETO LT; ARCE-GOMEZ BL; PETZL-ERLER ML\& QUEIROZ-TELLES F. HLA-A29 and genetic susceptibility to chromoblastomycosis. J Med Vet Mycol 27: 181-185, 1989.

41 - PETZL-ERLER ML; BELICH MP \& QUEIROZ-TELLES F. Association of mucosal leishmaniasis with HLA. Hum Immunol 32: 254-260, 1991.

42 - GOLDANI LZ; MONTEIRO CMC; DONADI EA; MARTINEZ R \& VOLTARELLI JC. HLA antigens in Brazilian patients with paracoccidioidomycosis. Mycopathologia 114: 89-91, 1991.

43 - VISENTAINER JEL; TSUNETO LT; MOLITERNO RA \& TELLES FILHO FQ. Lack of association between paracoccidioidomycosis and HLA histocompatibility antigens. Rev Bras Genet 16: 1035-1041, 1993.

44 - CABELLO PH; KRIEGER H; LOPES JD \& SANT'ANA EJ. On the association between ;HLA-A1 and B5 and clinical forms of schistosomiasis mansoni. Mem Inst Oswaldo Cruz 86: 37-40, 1991.

45 - EIZIRIK DL; MONTEIRO CMC; VOLTARELLI JC \& FOSS MC. Frequency of HLA antigens in a Brazilian type I diabetic population. Braz J Med Biol Res 20: 533-537, 1987.

46 - MEIRA DA; PELLEGRINO JJ; MACHADO JM; TSUJY K; MATSUOKA ES; HAIDA E \& KHOURY ABE. Frequency of human leukocyte antigen (HLA) in patients with malaria and in the general population of Humaita country, Amazonas state, Brazil. Rev Soc Bras Med Trop 20: 153-158, 1987.

47 - DIAS TE; FERNANDEZ RNM \& VILLA JA. Estudo da correlação HLA e miastenia gravis em uma população brasileira. Arq Neuropsiquiatr 48: 49-54, 1990.

48 - ELIAS LLK; VOLTARELLI JC \& MOREIRA AC. Adrenal response to adrenocorticotropin hormone and HLA typing of subjects with different degrees of 21-hydroxylase deficiency. Braz J Med Biol Res 26: 177-189, 1993.

49 - LIMA MG; DEGOS F; LEPAGE V; GIRAUD MC \& DEGOS L. Antígenos HLA em hepatite crônica ativa. Rev Bras Alergia Imunopatol 7: 18-20, 1984.

50 - STILMAN RF; PORTA G \& DELIMA MG. Antígenos HLA em crianças portadoras de hepatite crônica ativa autoimune e criptogênica. Rev Bras Alergia Imunopatol 12: 194-197, 1989.

51 - TORRES EA; SIVA MRBM; BORTOLOZZI J; PELLEGRINO-JR J \& DELIMA MG. Complexo HLA e glaucoma crônico simples. Rev Bras Alergia Imunopatol 12: 198-201, 1989.

52 - SOUZA NV. Distribuição dos antígenos HLA em 100 pacientes com descolamento de retina. Arq Bras Oftamol 45: 90-93, 1982.
53 - JOBIM LF; NEUMANN J; CORREA MC; TRACHTENBERG A; MORAES EK \& SARAIVA PJ. Angioedema hereditário: revisão, apresentação de uma família com 15 indivíduos afetados e correlação com o sistema HLA. Rev AMRIGS 26: 202206, 1982.

54 - SCHEINBERG MA \& SAMPAIO BJ. HLA-DR em casos de artrite reumatóide. Introdução de um novo marcador de agressividade clínica. Rev Paul Med 101: 154-157, 1983.

55 - GUAL RMR; CARVALHO IF; VOLTARELLI JC \& DONADI EA. Juvenile rheumatoid arthritis: clinical and immunogenetic aspects of a series of Brazilian patients. Rev Bras Reumatol 36: 115-119, 1996.

56 - YOSHINARI NN; PASTOR EH; OLIVEIRA MA; ROSALES T; CORDONI R \& COSSERMELLI W. Estudo dos antígenos HLA-A e HLA-B em portadores de lúpus eritematoso sistêmico. Rev Hosp Clin Fac Med São Paulo 39: 208-214, 1984.

57 - BALTHAZAR PA; GABRIELAJ; OLIVEIRA DP; OLIVEIRAMAX; ROSALES T; IGLESIAS SS; ASSAD RL \& COSSERMELLI W. HLA-DR em portadores de lúpus eritematoso sistêmico com anticorpos anti-ribonucleoproteína e na doença mista do tecido conjuntivo. Rev Hosp Clin Fac Med São Paulo 40: 249-253, 1985.

58 - YOSHINARI NH; GUADITANO G; MARCHIORI PE; OLIVEIRA D; ROSALES Y; MAEDA LC \& MUNIZI. Antígenos HLA-Ae HLA-B em de lúpus eritematoso sistêmico com envolvimento renal. Rev Hosp Clin Fac Med São Paulo 43: 228-231, 1988.

59 - SILVA LM \& DONADI EA. Is immunogenetic susceptibility to neuropsychiatric systemic lupus erythematosus (SLE) different from non-neuropsychiatric SLE? Ann Rheum Dis 55: 544-547, 1996.

60 - DONADI EA; SMITH AG \& CARVALHO IF. Molecular analysis of HLA antigens and alleles in the unusual association of idiopathic myasthenia gravis, seropositive rheumatoid arthritis, and d-penicillamine induced myasthenia gravis and Graves'disease. Rev Bras Reumatol 37: 305-308, 1997.

61 - ARRUDA WO; PETZL-ERLER ML; CARDOSO MA; LEHNER T \& OTT J. Late-onset autossomal dominant cerebellar ataxia. A family description and linkage analysis with the HLA systems. Arq Neuropsiquiatr 49: 285-291, 1991.

62 - DEGHAIDE NHS; DANTAS RO \& DONADI EA. HLA class and II profiles of patients presenting with Chagas'disease. Dig Dis Sci 43: 246-252, 1998.

63 - MACIEL LMZ; NAVARRO PAAS; RODRIGUES SS; IAZIGI N \& DONADI EA. Antígenos de histocompatibilidade de classe II em pacientes brasileiros portadores de doença de Graves com ou sem exoftalmia. Arq Bras Endocrinol Metabol 41: 76-81, 1997.

64 - KRAEMER MHS; DONADI EA; TAMBASCIA MA; MAGNA LA \& PRIGENZI LS. Relationship between HLA antigens and infectious agents in contributing towards the development of Graves'disease. Immunol Invest 27: 17-29, 1998.

65 - DONADI EA; VOLTARELLI JC; PAULA-SANTOS CM; KIMACHI T \& FERRAZ T. Association of Alport's syndrome with HLADR2 antigen in a group of unrelated patients. Braz $\mathbf{J}$ Med Biol Res 31: 533-537, 1998. 
66 - SELLAM; DONADI EA; VOLTARELLI JC; OLIVEIRA VC; BIRAL AC; THOMAS EM; BRANDALISE SR; MAGNA LA; TEIXEIRA MP; ARANEGA VL \& KRAEMER MHS. Population and family studies of histocompatibility antigens in acute leukemias and aplastic anemia. In: CHARRON D, ed. Genetic diversity of HLA: Functional and medical implications, EDK Medical and Scientific International Publisher, Paris, p. 763765, 1997.

67 - DONADI EA; SMITH AG; LOUZADA-JR P; VOLTARELLI JC \& NEPOM GT. HLA class I and II profiles of patients presenting with Sydenham's chorea. J Neurol. (In publication).

68 - GRAN JJ \& HUSBY G. Ankylosing spondylitis: prevalence and demography. In: KLIPPEL JH \& DIEPPE PA, eds. Rheumatology, Mosby, St. Louis, p. 24.1-6, 1994.

69 - NEPOM GT. Class II antigens and disease susceptibility. Annu Rev Med 46: 17-25, 1995.

70 - HILL AV; ALLSOPP CE; KWIATKOWSKI D; ANSTEY NM; TWUMASI D; ROWE PA; BENNETT S; BREWSTEN D; MCMICHAEL AJ \& GREENWOOD BM. Common West African HLA antigens are associated with protection from severe malaria. Nature 352: 595-600, 1991.

71 - HILLAV; ELVIN J; WILLIS AC; AIDOO M; ALLSOPP CE; GOTCH FM; GAO XM; TAKIGUSHI M; GREENWOOD BM \& TOWNSEND AR. Molecular analysis of the association of HLA-B53 and resistance to severe malaria. Nature 360: 434-439, 1992.

72 - OLERUP O; TROYE-BLOMBERG M; SCHREUDER GM \& RILEY EM. HLA-DR and -DQ gene polymorphism in West Africans is twice as extensive as in North European Caucasians: evolutionary implications. Proc Natl Acad Sci USA 88: 84808484, 1991.
73 - HILL AVS; ALLSOPP CEM \& KWIATKOWSKI D. Extensive genetic diversity in the HLA class II region of Africans, with a locally predominant allele, DRB $1 * 1304$. Proc Natl Acad Sci USA 89: 2277-2281, 1992.

74 - CERNA M; FERNANDEZ-VINA M; FRIEDMAN H; MORAES JR; MORAES ME; DIAZ L \& STATSNY P. Genetic markers for susceptibility to endemic Brazilian pemphigus foliaceus (fogo selvagem) in Xavante Indians. Tissue Antigens 42: 138140, 1993.

75 - WATANABE Y; TOKUNAGA K \& MATSUKI K. Putative amino acid sequence of HLA-DRB chain contributing to rheumatoid arthritis susceptibility. J Exp Med 169: 22632268, 1989.

76 - AWATA T; KUZUYA T; MATSUDA A; IWAMOTO Y; OKUYAMA $M$ \& JUJI T. High frequency of aspartic acid at position 57 of HLA-DR?-chain in Japanese IDDM patients and nondiabetic subjects. Diabetes 39 : 266-269, 1990.

77 - INOUE D; SATO K; ENOMOTO T; SUGAWA H; MAEDA M; INOKO H; TSUJI K; MORI T \& IMURA H. Correlation of HLA types and clinical findings in Japanese patients with hyperthyroid Graves' disease: evidence indicating the existence of four subpopulations. Clin Endocrinol 36: 75-82, 1992.

78 - TIWARI JL \& TERASAKI PI, eds HLA and disease association. Springer-Verlag, New York, 1985, 472 p.

Recebido para publicação em 14/01/2000

Aprovado para publicação em 03/03/2000 